Olgu Sunumu/Case Report

\title{
Uterin adenosorkom : Dört olgunun klinikopatolojik değerlendirmesi
}

Uterin adenosarcoma : Clinicopathologic evaluation of the four cases

Mehmet Kefeli ${ }^{*}$, Levent Yıldız $^{a}$, Handan Çelik $^{b}, \operatorname{Oğuz~Aydın~}^{a}$, Bedri Kandemir $^{a}$

a Ondokuz Mayıs Üniversitesi, Tip Fakültesi, Patoloji Anabilim Dal, Samsun

b Ondokuz Mayıs Üniversitesi, Tıp Fakültesi, Kadın Hastalıkları ve Doğum Anabilim Dalı, Samsun

\begin{tabular}{|c|c|c|}
\hline \multicolumn{2}{|c|}{ MAKALE BİLGİLERİ } & ÖZET \\
\hline \multicolumn{2}{|c|}{ Makale Geçmişi: } & Adenosarkom kadın genital sisteminin nadir görülen bir tümörüdür. Benign epitelyal ve \\
\hline Geliş & $19 / 09 / 08$ & malign stromal komponent içerir. Uterin sarkomların \%8'ini oluşturmaktadır. Endomet- \\
\hline Kabul & $23 / 01 / 09$ & riumdan kaynaklanan polipoid kitle olarak saptanır ve myometriuma invaze olabilir. Ya- \\
\hline
\end{tabular}

Ondokuz Mayıs Üniversitesi,

Tıp Fakültesi, Patoloji A.D.,

Kurupelit, Samsun

e-posta : mehmetkefeli@gmail.com

\section{Adenosarkom \\ Uterus \\ Klinik \\ Patoloji \\ Endometrium \\ Polipoid kitle \\ Keywords: \\ Adenosarcoma \\ Uterus \\ Clinic \\ Pathology \\ Endometrium \\ Polypoid mass}

Anahtar Kelimeler:

\begin{abstract}
Adenosarcoma is a rare tumor in the female genital tract. It contains benign epithelial and malignant stromal component. It consist of $8 \%$ of uterine sarcomas. They present as polypoid masses arising from the endometrium and can invade the myometrium. In our paper, we present four case of uterine adenosarcoma and their clinico-pathologic features. J. Exp. Clin. Med., 2009; 26:190-192
\end{abstract}

\section{Giriş}

Adenosarkom benign epitelyal ve malign mezankimal komponent ile karakterize nadir görülen bir tümördür. S1klıkla endometriumda izlenmekle birlikte servikste ve fallopian tüp, over ve paraovarian dokular gibi uterus dışı pelvik lokalizasyonlarda da görülebilir (Zaloudek ve Hendrickson, 2002). Epitelyal komponent genellikle inaktif veya proliferatif endometrial glandlara, mezankimal komponent ise endometrial stromal sarkoma benzer. Yazımızda uterus kaynaklı adenosarkom tanısı alan dört olgu klinikopatolojik özellikleri vurgulanarak sunulmuştur.
C 2009 OMÜ Tüm Hakları Saklıdır.

\section{Olgu Bildirimi}

Olguların hepsi postmenapozal dönemde olup yaş ortalamas1 70 (68-75)'dir. Olguların üçü postmenapozal kanama, bir tanesi de karında dolgunluk hissi ve ağrı yakınması ile Kadın Hastalıkları ve Doğum kliniğimize başvurdu. Tüm olgulara klinik değerlendirmeyi takiben total abdominal histerektomi ve bilateral salfingooferektomi operasyonu uyguland1.

Makroskopik olarak tümörlerin tümü endometrial kaviteyi dolduran polipoid kitleler şeklindeydi. Tümörlerin çapı ortalama 8,5 (5-12) cm idi. Kitleler yumuşak k1vamda ve kesit yüzeyleri gri-kahverengi renkteydi. 


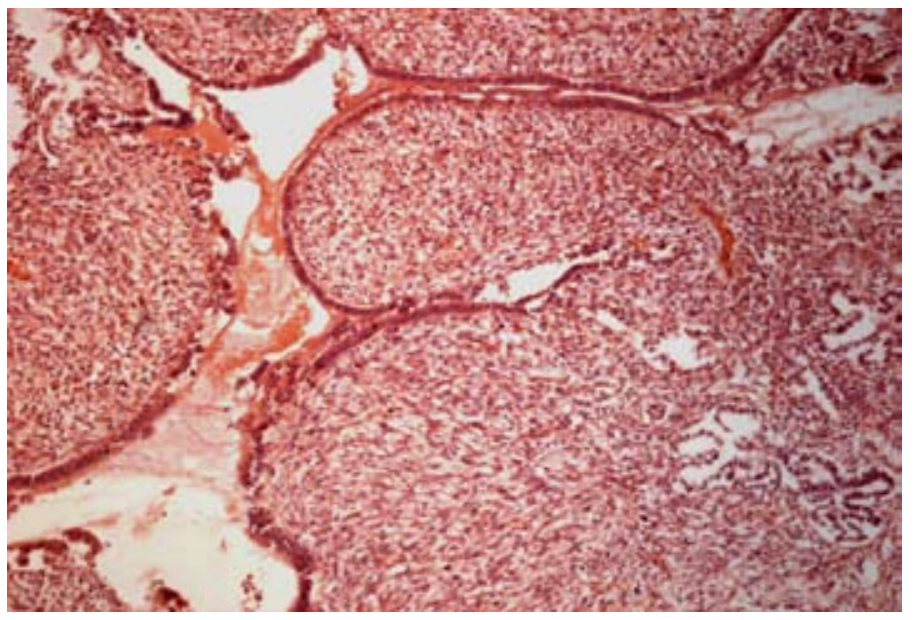

Şek. 1,a. Benign epitelyal ve malign mezankimal komponent (H\&E, x100).

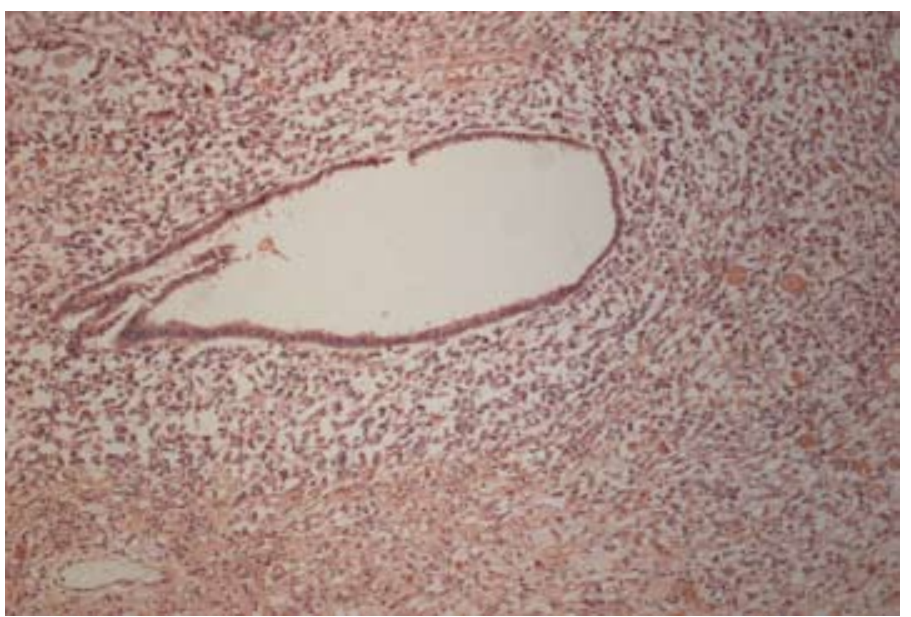

Şek. 1,b. Benign epitelyal ve malign mezankimal komponent (H\&E, x 100).

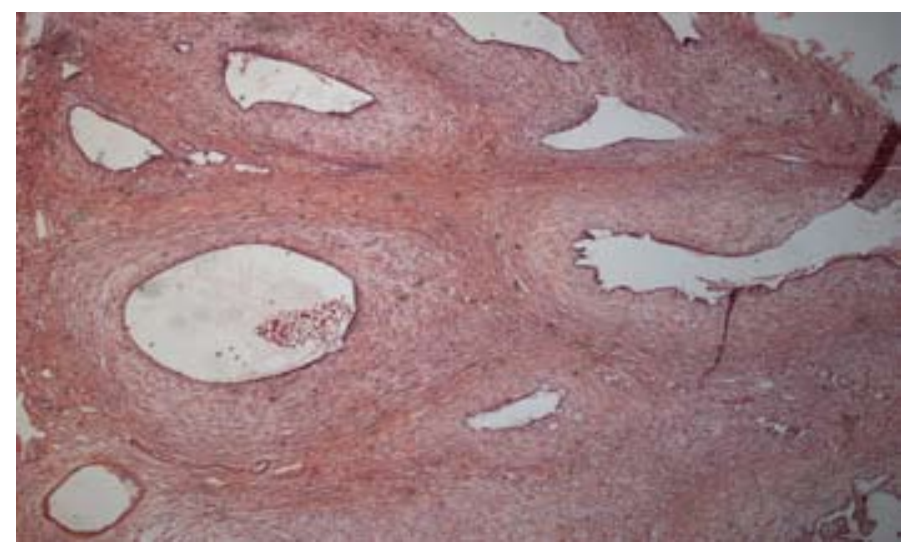

Şek. 2. Periglandüler stromal hiperselülarite (H\&E, x 25).

Mikroskopik olarak olguların hepsinde epitelyal komponent inaktif veya proliferatif endometrial glandlara benzemekteydi (Şek. 1a,b). Olguların tümünde adenosarkomların bir özelliği olan periglandüler stromal hiperselülarite mevcuttu (Şek. 2). Bir olguda epitelde müsinöz metaplazi saptandı. Mezankimal komponent ise düşük dereceli stromal sarkom ile karakterizeydi. Olguların tümünde epitelyal komponentte sitokeratin (clone AE1/AE3, Neomarkers), mezenkimal komponentte vimentin (Clone V9, Neomarkers) ve değişen yoğunlukta SMA (Clone 1A4, Labvision) pozitifliği saptandi. Dört olgudan ikisinde heterolog komponent mevcuttu. Heterolog komponent bir olguda çizgili kas, bir olguda ise kıkırdak yönünde farklanma göstermekteydi (Şek. 3). Sarkomatöz aşırı büyüme bir olguda mevcuttu. Myometrial invazyon üç olguda gözlenmezken bir olguda tümör myometriumun $1 / 2$ 'sinden daha azına invaze olmaktaydı. Olguların histopatolojik özellikleri Tablo 1'de özetlendi. Olguların hiçbirinde derin myometrial invazyon olmadığından postoperatif radyoterapiye gerek duyulmadi.

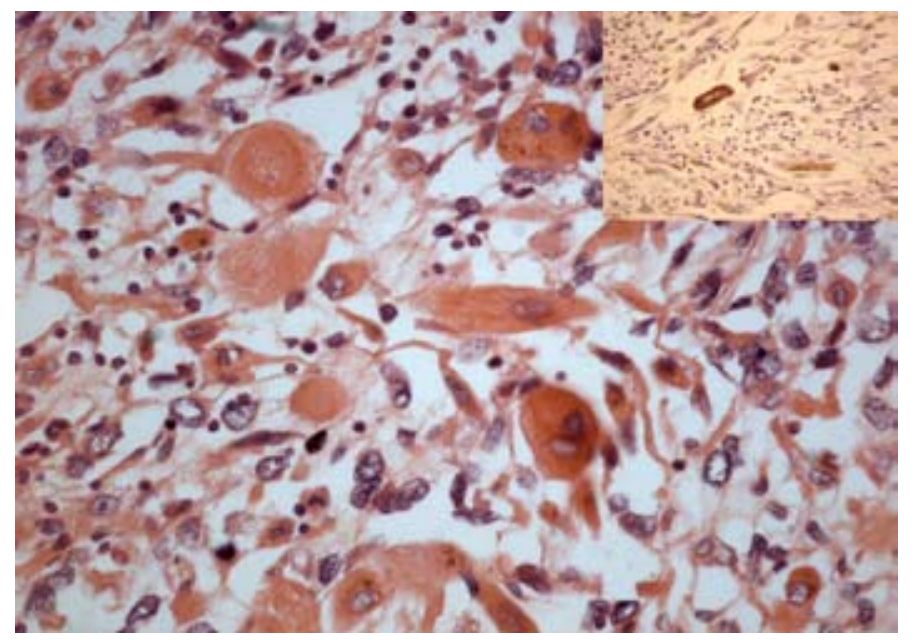

Şek. 3. Rabdomyosarkomatöz heterolog eleman ve immünohistokimyasal desmin pozitifliği (H\&E, DAB, x 400).

\section{Tartıșma}

Adenosarkomlar ilk kez Clement ve Scully tarafinda 1974 yılında tanımlanmış uterusun oldukça nadir görülen benign epitelyal komponent ve sarkomatöz stromal komponentle karakterize mikst epitelyal-mezankimal tümörleridir (Clement ve Scully, 1974). Uterusun malign mezankimal tümörleri tüm uterin malignitelerin \%2-3'ünü oluşturur. Adenosarkomlar ise uterin sarkomların \%8'ini oluştururlar (Clement ve Scully, 1990; Zaloudek ve Hendrickson, 2002).

Tablo 1: Olguların histopatolojik özellikleri.

\begin{tabular}{|c|c|c|c|c|c|c|c|}
\hline Olgular & Yaş & $\begin{array}{c}\text { Tümör } \\
\text { Capı }\end{array}$ & $\begin{array}{c}\text { Heterolog } \\
\text { Komponent }\end{array}$ & $\begin{array}{c}\text { Sarkomatöz } \\
\text { Așırı Büyüme }\end{array}$ & Mitoz & $\begin{array}{c}\text { Myometrial } \\
\text { İnvazyon }\end{array}$ & $\begin{array}{c}\text { Periglandüler } \\
\text { Hiperselülarite }\end{array}$ \\
\hline Olgu 1 & 70 & $11 \mathrm{~cm}$ & Var (RMS) & Var & $7 / 10 \mathrm{BBA}$ & Var & Var \\
\hline Olgu 2 & 75 & $6 \mathrm{~cm}$ & Var & Yok & $8 / 10 \mathrm{BBA}$ & Yok & Var \\
\hline Olgu 3 & 68 & $5 \mathrm{~cm}$ & Var & Yok & $3 / 10 \mathrm{BBA}$ & Yok & Var \\
\hline Olgu 4 & 68 & $12 \mathrm{~cm}$ & $\begin{array}{c}\text { Var } \\
\text { (Kıkırdak) }\end{array}$ & Yok & $5 / 10 \mathrm{BBA}$ & Yok & Var \\
\hline
\end{tabular}


Adenosarkomlar tüm yaş gruplarında (15 ile 90 yaş arası) izlenebilmekle birlikte genellikle posmenapozal dönemde görülmektedir. Ortalama görülme yaş1 $58^{\prime}$ dir (Clement ve Scully, 1990). Bizim serimizdeki dört olguda postmenapozal dönemdeydi. Makroskopik olarak genellikle endometrial kavite içerisine büyüyen ekzofitik polipoid kitle olarak izlenir. Genellikle tek bir kitle olarak ortaya çıkmakla birlikte birden çok polipoid kitle olarak da izlenebilmektedir (Zaloudek ve Hendrickson, 2002; McCluggage ve ark., 2003). Mikroskopik olarak ise benign glandüler ve malign mezankimal komponent ile karakterizedir. Epitelyal komponent genellikle inaktif veya proliferatif endometrial glandlara, mezankimal komponent ise düşük dereceli stromal sarkoma benzer. Olguların \%10-15'inde sarkomatöz komponent içerisinde heterolog elemanlar izlenebilir. Bu sıklıkla çizgili kas, daha nadiren kıkırdak, yağ ve diğer mezankimal elemanlar ile karakterizedir (McCluggage ve ark., 2003). Bizim dört olgumuzun ikisinde heterolog elemanlar izlendi. Bunlardan biri rabdomyosarkom, diğeri ise kıkırdak dokudan ibaretti.

Adenosarkomların çoğu düşük malignite potansiyelli tümörlerdir. Myometrial invazyon ve heterolog komponent varlığı kötü prognostik faktör olarak belirtilmektedir (Zaloudek ve Norris, 1981; McCluggage ve ark., 2003). Derin myometrial invazyon gösteren olguların \%24'ünde rekürrens bildirilmiştir (McCluggage ve ark., 2003). Seyri etkileyen en önemli histopatolojik özelliklerden biri sarkomatöz aşırı büyümedir. Sarkomatöz aşırı büyüme tümörün toplam hacminin \%25 veya daha fazlasında pür sarkoma- töz komponent bulunması ile karakterizedir. Bu alanlarda epitelyal eleman izlenmez ve mezankimal komponent genellikle yüksek dereceli olup, selüler özellikte ve yüksek mitotik aktiviteye sahiptir (Blom ve Guerrieri, 1999; Zaloudek ve Hendrickson, 2002; McCluggage ve ark., 2003). Bu özellik sık rekkürens, metastaz ve yüksek mortalite ile ilişsilidir (Clement, 1989). Bizim olgularımızdan yalnız birinde sarkomatöz aşırı büyüme vardı ve bu olgu serideki tek myometrial invazyon gösteren olguydu.

Adenosarkomlar uterusun diğer sarkomlarından epitelyal komponentinin varlığ 1 ile, malign mikst mezodermal tümörden ise epitelyal komponentinin benign olmas1 ile ayrilır (Zaloudek ve Hendrickson, 2002). Adenosarkomun tamoksifen kullanımı ve pelvik radyasyon ile ilişkili olduğu düşünülmektedir (Seidman ve ark., 1999; Arici ve ark., 2000). Clement ve ark.'ları meme tümörü nedeniyle tamoksifen kullanımı ile ilişkili 6 adenosarkom olgusu bildirmişlerdir. Bizim serimizdeki 4 olguda da tamoksifen kullanımı ve radyoterapi öyküsü bulunmamaktadır.

Uterusun diğer mezankimal tümörleri ile kıyaslandığında daha iyi seyirli olan adenosarkomların tedavisinde histerektomi genellikle yeterlidir. Ancak özellikle sarkomatöz aşırı büyüme, derin myometrial invazyon ve vasküler invazyon varlığında tanıdan uzun süre sonra bile rekürrens ve metastaz saptanan olgular bildirilmiştir. $\mathrm{Bu}$ nedenle bu tür olguların uzun süre takip edilmesi gerekmektedir.

\section{KAYNAKLAR}

Arici, D.S., Aker, H., Yildiz, E., Tasyurt, A., 2000. Mullerian adenosarcoma of the uterus associated with tamoxifen therapy. Arch Gynecol. Obstet. 264, 105-107.

Blom, R., Guerrieri, C., 1999. Adenosarcoma of the uterus: a clinicopathologic, DNA flow cytometric, p53 and mdm-2 analysis of 11 cases. Int. J. Gynecol. Cancer. 9, 37-43.

Clement, P.B., 1989. Müllerian adenosarcomas of the uterus with sarcomatous overgrowth. A clinicopathological analysis of 10 cases. Am. J. Surg. Pathol. 13, 28-38.

Clement, P.B., Scully, R.E., 1974. Müllerian adenosarcoma of the uterus. A clinicopathologic analysis of ten cases of a distinctive type of müllerian mixed tumor. Cancer. 34, 1138-1149.

Clement, P.B., Scully, R.E., 1990. Mullerian adenosarcoma of the uterus: a clinicopathologic analysis of 100 cases with a review of the literature. Hum. Pathol. 21, 363-381.

Clement, P.B., Oliva, E., Young, R.H., 1996. Mullerian adenosarcoma of the uterine corpus associated with tamoxifen therapy: a report of six cases and a review of tamoxifen- associated endometrial lesions. Int. J. Gynecol. Pathol. 15, 222-229.

McCluggage, W.G., Haller, U., Kurman, R.J., Kubik-Huch, R.A., 2003. Mixed epithelial and mesenchymal tumours. In: Tavassoli FA, Devilee P, editors. World Health Organization Classification of Tumours. Pathology and Genetics of Tumours of the Breast and Female Genital Organs. Lyon: IARC Press,

Seidman, J.D., Wasserman, C.S., Aye, L.M., MacKoul, P.J., O'Leary, T.J., 1999. Cluster of uterine mullerian adenosarcoma in the Washington, DC metropolitan area with high incidence of sarcomatous overgrowth. Am. J. Surg. Pathol. 23, 809-814.

Zaloudek, C., Hendrickson, M.R., 2002. Mesenchymal tumors of the uterus. In: Kurman RJ, editor. Blaustein's Pathology of the Female Genital Tract. New York, Springer Verlag, 561-615.

Zaloudek, C.J., Norris, H.J., 1981. Adenofibroma and adenosarcoma of the uterus: a clinicopathologic study of 35 cases. Cancer. $48,354-366$ 